Role theory of schools and adolescent health

Chris Bonell PhD*, Professor of Public Health Sociology, Department of Public Health, Environments and Society, London School of Hygiene and Tropical Medicine, 15-17 Tavistock Place, London WC1H 9NS, UK

Sarah-Jayne Blakemore, Professor of Cognitive Neuroscience, Institute of Cognitive Neuroscience, University College London, 17-19 Queen Square, London WC1N 3AZ, UK Adam Fletcher, Honorary Professor of Health and Social Science, Department of Public Health, Environments and Society, London School of Hygiene and Tropical Medicine, 15-17 Tavistock Place, London WC1H 9NS, UK

George Patton, Professor of Adolescent Health Research, Murdoch Children's Research Institute, Royal Children's Hospital, Flemington Road, Parkville, Victoria 3052, Australia

*Corresponding author

$3902 / 4000$ words

59/75 references

1 figure 


\section{Role theory of schools and adolescent health}

\section{Summary}

Evidence that health and education are inter-linked is transforming investments in adolescence. But we lack a comprehensive theory of how schools influence health, which could guide and be tested through empirical studies. Drawing on neuroscience, sociology and other disciplines, we theorise that schools influence adolescent health by affecting: what roles are available for students to perform; what resources student performances can draw on; and how peer and teacher audiences respond. Some schools offer opportunities for diverse pro-school roles and maintain these via constructive feedback. Others focus narrowly on high academic attainment. Where pro-school roles are unavailable, are beyond students' resources or elicit negative audience responses, students may experience anxiety and invest instead in anti-school roles, particularly in later adolescence. Healthharming behaviours, such as violence and drug use, are central to anti-school roles because they can facilitate belonging and status within anti-school peer groups, and symbolise alternative transitions to adulthood.

148 words 


\section{Role theory of schools and adolescent health}

\section{Introduction}

Health and education are powerfully linked. ${ }^{1}$ Mental health and behavioural problems have profound effects on student engagement and educational attainment. ${ }^{2}$ Conversely, schools have equally substantial effects on health, with great variation between schools in rates of violence, and use of tobacco, alcohol and other drugs: differences that reflect school characteristics rather than merely differences between the students entering schools. ${ }^{3-5} \mathrm{~A}$ range of mechanisms has been suggested for these health benefits: avoidance of health risks associated with early entry into labour markets, sexual activity or criminality; ${ }^{6}$ educating young people about how to promote their physical and mental health; ${ }^{7}$ and provision of nurturing social environments, with growing evidence that interventions that modify the school environment also improve student mental and physical health across a range of outcomes. ${ }^{8-10}$

Such clear demonstrations of the effects of school on health are transforming approaches to investments in adolescence. ${ }^{11}$ Yet we still lack a comprehensive theory for how the school social environment affects the health and social development of students. Several existing theories are used to inform observational studies of differences in health outcomes between schools, as well as informing the logic models of school-based health interventions that are evaluated in trials. But these theories generally do not describe what specific features of the school environment other than in terms of student behaviours and peer relationships. ${ }^{12}$ For example, the social development model suggests that young people are more like to bond to school and other conventional social institutions when these provide individuals with opportunities for learning, skills development and rewards. ${ }^{13}$ It further proposes that such bonds will reduce young people's involvement with 
delinquent peers and hence engagement in anti-social behaviours. However, the model does not aim to describe specific features of the school environment that will promote bonding. Furthermore, it only considers health risks arising from anti-social behaviours, and does not describe how bonding to conventional institutions will reduce involvement with delinquent peers. This lack of pertinent theory matters because without a plausible (and empirically testable) theory, our ability to interpret and learn from empirical studies is limited, as is our ability to develop and test interventions that might modify the school social environment.

The theory of human functioning and school organisation is arguably the most comprehensive available theory of how school environments influence health. ${ }^{14}$ It proposes that, for students to adopt healthier rather than riskier behaviours, they should be able to reason and to relate to others who will support such decisions. Within this framework, students are more likely to develop such relationships if 'committed' to school, in terms of the school 'instructional order' (i.e. academic learning) and 'regulatory order' (i.e. norms for conduct). Commitment is more difficult for socioeconomically disadvantaged students because of a disjunction between the class-based culture of the school and that of students' families and neighbourhoods. To build student commitment, particularly among socio-economically disadvantaged students, schools should 're-frame' learning and erode various 'boundaries'. Reframing learning helps ensure that it addresses students' needs and preferences. Boundary erosion can enhance relationships between: students and teachers (so that they can interact more collaboratively); academic subjects (so that students can reflect on how these relate to their own lives); and schools and local communities (so that schools are less culturally distant from family and neighbourhood cultures). The theory predicts that rates of risk behaviours will be lower in schools in which more students are committed to learning and feel a sense of belonging in school, and in schools in which school life is focused on student preferences and characterised by strong connections between staff and students, academic learning and broader development and school and neighbourhood. 
However, despite this clear focus on how school environments might influence health, the theory of human functioning and school organisation has a number of limitations. Firstly, like other theories such as the social development model, ${ }^{13}$ it does not consider adolescent cognitive and socialemotional development, and so does not consider how the effects of school environment might vary by student age or developmental stage, including the effects of peer groups and emerging sexuality. Secondly, although the theory engages with how socio-economic status might affect experience of school, it does not consider how other characteristics, such as gender or ethnicity, might affect commitment to school and decisions about health-related behaviours. Thirdly, the theory does not address how schools might affect mental health, despite there being evidence that schools exert small but significant effects on various mental health outcomes. ${ }^{5}$ Finally, the theory is only partially supported by empirical evidence. There is evidence that rates of risk behaviours are lower in schools in which more students feel committed to learning and a sense of belonging, and report better relationships with teachers, ${ }^{15-20}$ particularly for students of low socio-economic status. ${ }^{21}$ There is also evidence from randomised trials that interventions to build a sense of commitment and inclusion within secondary schools promote various measures of physical and mental health. ${ }^{8,22,23}$ However, there is less evidence that student risks are lower, and commitment higher, in schools that focus on student preferences. ${ }^{21,24}$

In this paper, we draw on developmental cognitive neuroscience and psychology, sociology and education to extend existing theories about the influence of school social environments on health, focusing on those catering for students from early adolescence (secondary schools in the UK; middle and high schools in the US and other systems). Cognitive neuroscience and psychology have made advances in understanding how cognitive processes change in adolescence and how these might help explain heightened risk-taking and other adolescent behaviours. Importantly for our theory, much recent research indicates that sensitivity to peer influence of a wide variety of behaviours is 
stronger in adolescence than either childhood or adulthood, and that adolescents generally take more risks when with friends because the presence of peers change how they make decisions. ${ }^{25-27}$ Research also suggests that sensitivity to, and stress arising from, peer exclusion, and need for belonging, are generally greater among adolescents. ${ }^{28}$ Sociological and educational scholarship has made advances in understanding that young people can make rational choices to engage in risk practices when these serve practical and symbolic purposes. ${ }^{29}$ Qualitative studies suggest that students can practice risk behaviours, such as drug use or violence, when these facilitate entry into or symbolise belonging or status with 'anti-school' peer groups, and that this is more likely to happen among students who derive little sense of belonging or status from learning and other 'proschool' activities. ${ }^{30}$

\section{Role selection, performance and emerging identity}

We propose a theory of school influences on health that understands health-related risk behaviours and mental health problems as arising within the context of students playing various roles before an audience of teachers and peers. Thinking about behaviour and interactions in terms of 'roles' and 'audiences' was developed by Erving Goffman in his dramaturgical approach to sociology, using the metaphor of theatrical performances. ${ }^{31}$ Such analyses view individuals as using performances to manage an audience's impression of them, and aiming to promote their belonging and status within social groups. Dramaturgical analyses stress that performances are precarious; a performer will aim for successful impression-management but there will, in any performance, be the risk of failure to convince, stigma and group exclusion.

Adolescents generally have the role of 'student' imposed but can choose a particular version or versions of this role to perform. Some students will typically perform pro-school roles of the engaged or compliant student, following school rules and staff expectations of what constitutes pro- 
school behaviour. This might include participating in class activities, staying on task, and completing their work. Other students will more typically perform anti-school roles, such as the disengaged or disruptive student: for example, not engaging in teacher-directed classroom activities, engaging in off-task interactions with peers, and insulting or challenging teachers. Many students will perform different roles in different contexts, with varying degrees of engagement or disengagement, dependant on which teachers and peers they are with and which lesson or other school activity they are engaged in. According to dramaturgical theory, students will tend to choose roles that maximise their chances of achieving belonging and status in their particular school and social group.

Not all students will be able to play all roles because schools will differ in what roles are available and because students will differ in what resources they can bring to these roles. In terms of the 'cast list' of available roles, some schools will have teachers focused almost exclusively on academic students or perhaps those excelling in arts or sports, so that the only pro-school roles will be in these categories. Other schools will recognise students playing a broader array of roles, such as the striving or well-behaved under-achiever, or the challenging student who is dealing with social problems in and out of school. In some very academic schools, it might be hard to play an anti-school role and find belonging with many peers. In other schools, it might be hard to play a pro-school role and find belonging with peers. In others, myriad roles will find acceptance with various peer groups. The cast list of available roles will also tend to vary with adolescents' progression through secondary school and their psychological development. In the early years of secondary school, student peer-group networks will have been disrupted by the transition from primary school; new peer groups will be forming but will initially tend to be relatively undifferentiated and unstable. ${ }^{32,33}$ Relationships will likely become more stable and reciprocal as students move through the school, and role choices more differentiated. 
As well as the availability of roles, there will also be variation in students' abilities to play various roles. As they progress through secondary school, adolescents will generally develop a greater desire for autonomy ${ }^{26}$ and for a personal sense of identity. ${ }^{26,34}$ Adolescents may therefore be less likely to choose to perform the role of committed learner unless schools make this attractive by allowing older students more freedom over what and how they learn and behave. Students will also vary in what resources they can bring to playing a particular role. We can think of these resources in terms of economic, cultural and social 'capital'. ${ }^{35,36}$ 'Economic capital' refers to money enabling actions: for example, a family having a quiet room for homework to enable an adolescent to perform the role of engaged student. 'Cultural capital' refers to learnt knowledge or skills enabling action: for example, a student being able to speak the same dialect as teachers, thus helping her perform the role of engaged learner. 'Social capital' refers to relationships and trust between individuals enabling action. This can be sub-categorised into 'bonding ties' with similar individuals and 'bridging ties' with different individuals: for example, a student having bonding ties with other engaged students and bridging ties with teachers, thus enabling her to perform the role of engaged student. ${ }^{37}$

Students of higher socio-economic status will generally possess more economic, cultural and social capital and will often find it easier to perform pro-school roles. Adolescents from lower socioeconomic groups or more deprived neighbourhoods might have fewer of the right forms of capital to draw on. They might also possess capital that actually impedes their ability to perform pro-school roles. For example, sociological studies suggest that students who have bonding ties with anti-school students or who possess cultural capital that helps them play adult-like roles outside school (such as gang-leader or carer for an ill parent), may find it harder to perform the role of committed student at school. ${ }^{38}$

It is less clear how arrays of capital will vary by ethnicity or gender; it will not simply be the case that minority-ethnic or female students will always possess less capital. This will depend on the 
particularities of groups in specific settings. Schools should be more successful in engaging students in pro-school roles where they aim to develop students' cultural and social capital equitably. Schools will generally be less successful in engaging all students where they distort some students' social capital: for example, by concentrating together students of lower socio-economic status in lowability streams. What constitutes the right cultural or social capital will also vary between schools. Schools with more diverse staffing may, for example, ensure that the cultural and social capital that students already possess can be used by them to interact with their teachers and perform proschool roles.

\section{Audience reaction and its impact on performers}

Student performances of roles occur before an 'audience' of teachers and peers. Any performance, such as that of engaged learner, school athlete or disruptive student, is precarious. Most students will reflect on their performances and audience reactions, assessing whether they have successfully managed the audience's impression of them, and whether this will promote their belonging and status within the group. Where an audience is unappreciative or hostile, this will likely cause the student to experience anxiety, possibly with implications discussed below for mental health, and/or to reassess whether they should continue to perform the role in question. Teacher reactions to performances will likely reflect the institution's expectations and its style of providing feedback. In the schools mentioned that offer only a narrow range of roles, expectations will tend to focus narrowly on whether students reach a certain standard. In other schools, expectations might also encompass the efforts students have made and their trajectory of achievement over time. In some schools, feedback will merely provide a summative judgement of attainment, while in others, feedback will also include constructive criticism and further learning. ${ }^{39}$ 
The reactions of the student audience to performances, for example of academic, sporting or disruptive performances, will also generally reflect their expectations and norms of what behaviour is socially appropriate. In some schools, students with norms supportive of academic work and attainment will be numerous and influential. In other schools, more anti-school peer groups will predominate so that norms may be more hostile to academic engagement and achievement. ${ }^{40}$ Norms will tend to evolve as students move through adolescence and through the school, influenced by the wider culture. For example, student audiences may be influenced by gender norms about whether academic engagement is acceptable among some groups of boys ${ }^{41}$ or whether involvement in sport is acceptable among some groups of girls. ${ }^{42}$

Performers will vary in how sensitive they are to audience reactions. Adolescence is associated with increasing awareness of others' perspectives, ${ }^{43,44}$ and increased susceptibility to peer influence ${ }^{25,26}$ and sensitivity to peer exclusion. ${ }^{28}$ In the course of adolescence, students tend to become more sensitive to audience reactions, from teachers but especially from other students. They will therefore be more likely to experience anxiety about performances, and to judge that a performance has failed and that they must change roles. Students may experience severe anxiety, particularly where audience reactions take the form of persistent personalised criticism from teachers, or persistent peer abuse and exclusion, ${ }^{45}$ and there is evidence that this increases vulnerability to depression. ${ }^{46}$ Some students may judge their performances inadequate, experiencing anxiety, even in the absence of such audience reactions, for example when they hold perfectionist attitudes towards academic achievement ${ }^{47}$ or heightened sensitivity and insecurity about their status among peers.

A student withdrawing from a particular pro-school role may decide to reinvest in performing an anti-school role where she perceives that alternative pro-school roles are not available, are not performable given the 'capital' she possesses, or that such roles will not enable her to develop a 
sense of belonging and status among peers. ${ }^{26,28,34}$ The need to perform anti-school roles to develop belonging with peers might be particularly acute in schools where students feel that staff will not protect them from violence. ${ }^{48,49}$

Systematic review of qualitative research suggests that where students are drawn to perform antischool roles, they may engage in health-related risk behaviours to facilitate their joining or gaining status in anti-school groups. ${ }^{30}$ Risk behaviours might include those that are overtly anti-social, such as violence, or underage or illegal substance use, or others such as early sexual debut, consumption of junk food and withdrawal from sport. What these behaviours have in common is that they can be used by adolescents to symbolise a transition to an adult sense of identity that nonetheless deviates from the sorts of transitions encouraged by the school. Schools generally aim to promote a transition to an adult sense of identity in terms of the observance of rules and investment in education or physical fitness for the future. Engagement in anti-school behaviours suggest an alternative sense of identity rooted in a disregard for such norms and a prioritisation of the present over the future. The particular behaviours performed will depend on the options that are available to and culturally resonant for students, depending on their age and social environment. ${ }^{50}$ Different age groups will tend to have different access to particular substances, such as tobacco, alcohol, cannabis and other drugs. Sexual behaviour will generally be more feasible for older than younger adolescents. Different substances or forms of violence might have cultural cache in some communities but not others. ${ }^{51,52}$ Withdrawal from sport or engagement in unhealthy dieting may have symbolic meaning for particular groups, such as girls influenced by sexist media imagery. ${ }^{53}$

Thus, students' physical and mental health can be influenced by their performance of roles in schools. This can occur directly, as a result of the stress experienced in playing roles or as a result of negative audience responses and exclusion from peer groups leading to mental health problems and potentially risk of self-harm or suicide. ${ }^{54,55}$ Such risks will tend to increase in the course of 
adolescence as sensitivity to peer influence and exclusion increases. Threats to health can also occur indirectly, as a result of engagement in the health-related risk behaviours listed above. Such behaviours may influence mental and physical health in the short-term, for example via violence and substance use predisposing individuals to mental health harms or injuries. ${ }^{45}$ Risk behaviours, such as violence, substance use, unhealthy eating and physical inactivity, will also influence individuals' health over the life-course via increasing risks of non-communicable disease. ${ }^{56}$

Our theory proposes that school environments are an important influence on student health but is not overly deterministic; we do not deny that other factors will also be important. Inevitably, some students who are not performing anti-school roles will adopt some of the health-related risk behaviours listed above. Some students will also experience anxiety as a result of performing proschool roles and not only anti-school roles, including where pressure from teachers or parents for academic achievement is intense. However, our theory suggests that overall rates of risk behaviours will be higher among students who are taking on disengaged, anti-school roles because of their symbolic importance to such students. Our theory also suggests that overall rates of anxiety and emotional problems will generally be more common among disengaged students since these students will tend to have less social support in schools as a result of their not playing pro-school roles.

\section{Conclusion: role theory of schools and adolescent health}

In summary, we propose a role theory of schools and adolescent health (figure 1). Schools influence adolescents' health and wellbeing by affecting how they can perform the role of student in school, with students performing anti-school roles more likely to engage in health-related risk behaviours, and experience anxiety and mental health problems. 
All adolescents must adopt one or more student roles, which range from pro-school roles, such as the committed learner, to anti-school roles, such as the disruptive student. All adolescents make an active and creative choice of which roles to perform and how. But their choices and performances are both enabled and constrained by the school environment, as well as the resources, in the form of economic, cultural and social capital, that students possess. The cast list of available roles differs between schools. Students' economic, cultural and social capital may vary by socioeconomic status, gender and ethnicity. Performances of pro- and anti-school roles are precarious, depending on the responses of audiences of teachers and peers. Teacher responses are influenced by the schools' norms about expectations (focused narrowly on absolute achievement or also encompassing effort and trajectory) and styles of feedback (focused on summative assessment or also constructive feedback). Peer responses are also influenced by local norms, including those relating to views on academic engagement as well as those about gender roles.

Negative audience responses will likely arouse anxiety and may encourage an adolescent to switch roles. With a movement into puberty, students tend to become increasingly sensitive to peer influence and risk of exclusion, and more prone to experience anxiety and therefore withdrawal from pro-school roles. Where students cannot satisfy their need for belonging and status by performing pro-school roles, they are likely to switch to anti-school roles as an alternative means of achieving these ends. Critically for our theory of school influences on health and wellbeing, such roles often involve the performance of symbolically important health-related risk behaviours. Furthermore, performances of such roles may bring with them higher levels of anxiety. Students performing anti-school roles are more likely to engage in risk behaviours and experience anxiety than students in pro-school roles.

A scientific theory needs to be able to inform hypotheses that are open to empirical assessment of falsifiability. Below, we hypothesise how features of the school environment might interact with 
student characteristics to influence rates of risk behaviours and mental health problems. We predict that schools which:

- offer diverse activities through the academic curriculum, pastoral roles and extra-curricular activities (so that there are more diverse pro-school roles) will have higher rates of student commitment and lower rates of student risk behaviours and emotional problems;

- make pro-school roles more attractive by offering graduated autonomy in learning and other aspects of school life (so that more students remain in pro-school roles as they grow older) will also have higher student commitment and lower risk behaviours and emotional problems among older students;

- assess student performances in terms of effort and trajectory, and which provide constructive feedback (so that more students persist with pro-school roles), will have higher student commitment, and reduced student risk behaviours and emotional problems, than schools that focus narrowly on absolute achievement, particularly among older students;

- have higher equity in academic achievement and more diverse staffing in terms of socioeconomic status, ethnicity and gender (so that more students possess social and cultural capital that enables them to engage with staff and perform pro-school roles) will have higher commitment and reduced risk behaviours and emotional problems among these groups; and

- cluster socially disadvantaged students together, for example in low-ability streams (so that such students are less likely to build bridging social capital with pro-school students), will have lower student commitment and increased risk behaviours among these such students, particularly in later adolescence.

We extend previous theories by incorporating a life course and developmental perspective on the roles and emerging identity of adolescents in their school contexts. Whereas previous theory has 
emphasised schools offering opportunities and rewards for learning ${ }^{13}$ or reframing learning towards student preferences and eroding boundaries, ${ }^{14}$ our theory focuses on whether schools equitably provide students with a diverse repertoire of pro-school roles and sufficient support that students maintain participation in these. Unlike previous frameworks, our theory suggests that participation in school roles can sometimes generate harms, for example via the anxiety performance of such roles can evoke. Furthermore, our theory recognises that students are active and creative agents exercising choices, but with these choices being enabled and constrained by their emerging psychological dispositions, by the economic, cultural and social capital they possess, and by the school environment. Our theory is however almost wholly informed by evidence from developmental cognitive neuroscience and psychology, education and sociology conducted in highincome Western countries and so may be less pertinent to other settings.

We recommend that future empirical studies explore the hypotheses set out above. Observational studies could examine school- and student-level influences on adverse health outcomes. ${ }^{3}$ Randomised trials could assess the effectiveness of interventions with logic models informed by our theory as a further means of empirically assessing this. ${ }^{57}$ We intend to write a further paper operationalising our theory so that it might inform theories of change of future interventions, but, in short, our theory suggests that such interventions should: increase the diversity of academic and pastoral roles for student, including as health buddies and peer educators ${ }^{58}$; offer extra-curricular activities in the domains of sports, arts and community service, for example as included in schoolbased positive youth development programmes, ${ }^{59}$ grant older students more say in decisions, as is the case in some whole-school interventions; $;^{8,22,23}$ and ensure schools address discrimination according to students' socioeconomic status, ethnicity, gender and sexuality.

\section{Author contributions}


CB conceived the idea for the paper and wrote the first draft. SJB conceived the sections of the paper concerning cognitive neuroscience and edited successive drafts of the paper. AF advised on sociological research and drafted figure 1. GP conceived the sections of the paper concerning mental health and edited a draft of the paper.

\section{Declaration of interests}

The authors declare no interests in terms of financial interests or personal relationships relevant to this paper.

\section{Acknowledgements}

This development of this paper was unfunded. 


\section{References}

1. Bonell C, Jamal F, Harden A, et al. Systematic review of the effects of schools and school environment interventions on health: evidence mapping and synthesis. Public Health Research 2013; 1(1).

2. Suhrcke $M$, de Paz Nieves $C$. The impact of health and health behaviours on educational outcomes in highincome countries: a review of the evidence. Copenhagen: WHO Regional Office for Europe; 2011.

3. Aveyard A, Markham WA, Chenge KK. A methodological and substantive review of the evidence that schools cause pupils to smoke. Soc Sci Med 2004; 58: 2252-65.

4. Bonell $\mathrm{CP}$, Parry $\mathrm{W}$, Wells $\mathrm{H}$, et al. The effects of the school environment on student health: a systematic review of multi-level studies. Health and Place 2013; 21: 180-91.

5. Kidger J, Araya R, Donovan J, Gunnell D. The effect of the school environment on the emotional health of adolescents: a systematic review. Pediatrics 2012; 129(5): 925-49.

6. Patton G, Sawyer SM, Santelli JS, et al. Realising the Future of Global Health: A Lancet Commission on Adolescent Health and Wellbeing. Lancet 2016; 387((10036): 2423-78.

7. Bonell C, Humphrey N, Fletcher A, Moore L, Anderson R, Campbell R. Why schools should promote students' health and wellbeing Education policy shouldn't focus solely on academic attainment. British Medical Journal 2014; 348: g3078.

8. Bonell $C$, Allen $E$, Warren $E$, et al. Initiating change in the school environment to reduce bullying and aggression: a cluster randomised controlled trial of the Learning Together (LT) intervention in English secondary schools. Lancet 2018; 392(10163): 2452-64.

9. Bonell $\mathrm{C}$, Wells $\mathrm{H}$, Harden $\mathrm{A}$, et al. The effects on student health of interventions modifying the school environment: systematic review. J Epidemiol Comm Health 2013; 67(8): 677-81.

10. Langford R, Bonell CP, Jones HE, et al. The WHO Health Promoting School framework for improving the health and well-being of students and staff. Cochrane Database of Systematic Reviews 2011, Issue 1 Art No: CD008958 2014.

11. Fernandes G, Sridhar D. World Bank and the Global Financing Facility. BMJ 2017; 358: j3395.

12. Bonell $C$, Fletcher A, Jamal F, et al. Theories of how the school environment impacts on student health: Systematic review and synthesis. Health and Place 2013; 24: 242-9.

13. Hawkins JD, Weiss JG. The social development model: An integrated approach to delinquency prevention. Journal of Primary Prevention 1985; 6: 73-97.

14. Markham WA, Aveyard P. A new theory of health promoting schools based on human functioning, school organisation and pedagogic practice. Soc Sci Med 2003; 56(6): 1209-20.

15. Aveyard A, W.A. M, Lancashire E, Almond J, Griffiths R, Cheng KK. A cohort study to examine whether inter-school variation in smoking uptake is mainly due to differences in pupil composition or differences in schools. Health and Place 2005; 11(1): 55-65.

16. Aveyard P, Markham WA, Lancashire E, Bullock A, MacArthur C, Cheng KK. The influence of school culture on smoking among pupils. Soc Sci Med 2004; 58(9): 1767-870.

17. Bisset S, Markham WA, Aveyard P. School culture as an influencing factor on youth substance use. J Epidemiol Comm Health 2007; 61(6): 485-90.

18. Markham W. School culture and teenage substance use : a conceptual and operational framework. Ediucational Review 2015; 67(3): 282-99

19. Markham WA, Aveyard P, Bisset SL, Lancashire ER, Bridle C, Deakin S. Value-added education and smoking uptake in schools: a cohort study. Addiction 2008; 103(1): 155-61.

20. Tobler AL, Komro KA, Dabroski A, Aveyard P, Markham WA. Preventing the link between SES and high-risk behaviors: "Value-added" education, drug use and delinquency in high-risk, urban schools. Prevention Science 2011; 12(2): 211-21.

21. Bonell $C$, Beaumont $E$, Dodd $M$, et al. Effects of school environments on student riskbehaviours: evidence from a longitudinal study of secondary schools in England. J Epidemiol Comm Health Published Online First: 23 February doi: 101136/jech-2018-211866 2019. 
22. Flay BR, Graumlich S, Segawa E, Burns JL, Holliday MY. Effects of 2 prevention programs on high-risk behaviors among African American youth: a randomized trial. Arch Pediatr Adolesc Med 2004; 158(4): 377-84.

23. Patton G, Bond L, Carlin JB, et al. Promoting social inclusion in schools: group-randomized trial of effects on student health risk behaviour and well-being. Am J Public Health 2006; 96(9): 15827.

24. Shackleton N, Jamal F, Fletcher A, et al. Development and pilot of a new measure for empirically examining the theory of human functioning and school organisation. Critical Public Health DOI101080/0958159620161191619 2016

25. Chein J, Albert D, O'Brien L, Uckert K, Steinberg L. Peers increase adolescent risk taking by enhancing activity in the brain's reward circuitry. Developmental Science 2011; 14: F1-10.

26. Blakemore SJ. Avoiding social risk in adolescence. Current Directions in Psychological Science 2018; 27(2): 116-22.

27. Gardner $M$, Steinberg L. Peer influence on risk taking, risk preference, and risky decision making in adolescence and adulthood: an experimental study. Dev Psychol 2005; 41(4): 625-35.

28. Sebastian C, Viding E, Williams KD, Blakemore SJ. Social brain development and the affective consequences of ostracism in adolescence. Brain and Cognition 2010; 72(1): 134-45.

29. Fletcher A, Bonell C, Sorhaindo A, Strange V. How might schools influence young people's drug use? Development of theory from qualitative case-study research. J Adolesc Health 2009; 45(2): 126-32.

30. Jamal F, Fletcher A, Harden A, Wells H, Thomas J, Bonell C. The school environment and student health: a systematic review and meta-ethnography of qualitative research. BMC Public Health 2013; 13(1): 798.

31. Goffman E. The Presentation of Self In Everyday Life. New York: Doubleday; 1959.

32. Temkin DA, Gest SD, Osgood DW, Feinberg M, Moody J. Social network implications of normative school transitions in non-urban school districts. Youth and Society 2018; 50(4): 462-84.

33. Burnett Heyes S, Jih YR, Block P, Hiu CF, Holmes EA, Lau JYF. Relationship reciprocation modulates resource allocation in adolescent social networks: developmental effects. Child Dev 2015; 86(5): 1489-506.

34. Erikson EH. Identity: Youth and Crisis. New York: Norton; 1968.

35. Bourdieau P, Wacquant L. An Invitation to Reflexive Sociology. Chicago: University of Chicago Press; 1992.

36. Coleman JS. Social capital in the creation of human capital. The American Journal of Sociology 1988; 97(Supplement: Organizations and Institutions: Sociological and Economic Appraoches to the Analysis of Social Structure): S95-S120.

37. Granovetter M. The strength of weak ties. American Journal of Sociology 1973; 78: 1360-80.

38. Fletcher A, Bonell C. "Escaping from prison": Female students' substance use and the school environment. J Epidemiol Comm Health 2008; 62 (Suppl. 1): A10.

39. Rattan A, Savani K, Chugh D, Dweck CS. Leveraging mindsets to promote academic achievement: policy recommendations. Perspectives on Psychological Science 2015; 10(6): 721-6.

40. Willis P. Learning to Labour: How Working Class Kids Get Working Class Jobs. Aldershot: Saxon House; 1977.

41. Legewie J, DiPrete TA. School context and the gender gap in educational achievement. American Sociological Review 2012.; 77: 463-85. .

42. Spencer RA, Rehman L, Kirk SFL. Understanding gender norms, nutrition, and physical activity in adolescent girls: a scoping review. International Journal of Behavioral Nutrition and Physical Activity 2015; 12: 6.

43. Dumontheil I, Apperly IA, Blakemore SJ. Online usage of theory of mind continues to develop in late adolescence. Dev Sci 2010; 13: 331-8. 
44. Tamnes CK, Overbye K, Ferschmann L, et al. Social perspective taking is associated with selfreported prosocial behavior and regional cortical thickness across adolescence. Dev Psychol 10 '8; 54(9): 1745-57.

45. Bond L, Carlin JB, Thomas L, Rubin K, Patton G. Does bullying cause emotional problems? A retrospective study of young teenagers. Br Med J/ 2001; 323: 480-84.

46. Allen NB, Badcock PB. The social risk hypothesis of depressed mood: evolutionary, psychosocial, and neurobiological perspectives. Psychological Bulletin 2003; 129(6): 887-913.

47. Inglés CJ, García-Fernández JM, Vicent M, Gonzálvez C, Sanmartín R. Profiles of perfectionism and school anxiety: a review of the $2 \times 2$ model of dispositional perfectionism in child population. Frontiers in Psychology 2016; 7: 1403.

48. Fletcher A. Young people's experiences of school and drug use: systematic review and casestudy research. Thesis submitted for Ph.D. London: University of London; 2008.

49. Waldron LM. The messy nature of discipline and zero tolerance policies: Negotiating safe school environments among inconsistencies, structural constraints and the complex lives of youth. Sociological Studies of Children and Youth 2005; 11: 81-114.

50. Currie C, Molcho M, Boyce W, Holstein B, Torsheim T, Richter M. Researching health inequalities in adolescents: the development of the Health Behaviour in School-Aged Children (HBSC) Family Affluence Scale. Soc Sci Med 2008; 66: 1429-36.

51. Esteban McCabe S, Morales M, Cranford JA, Delva J, McPherson MD, Boyd CJ. Race/ethnicity and gender differences in drug use and abuse among college students. Journal of Ethnicity and Substance Abuse 2007; 6(2): 75-95.

52. Hurcombe R, Bayley M, Goodman A. Ethnicity and Alcohol: A Review of the UK Literature. York: Joseph Rowntree Foundation; 2010.

53. Westerberg-Jacobson J, Ghaderi A, Edlund B. A longitudinal study of motives for wishing to be thinner and weight-control practices in 7- to 18-year old Swedish girls. European Eating Disorders Review 2012;; 20: 294-302.

54. Mulvey KL, Boswell C, Zheng J. Causes and consequences of social exclusion and peer rejection among children and adolescents. Report on Emotional and Behavioral Disorders in Youth 2017; 17(3): 71-5.

55. Holt MK, Vivolo-Kantor AM, Polanin JR, et al. Bullying and Suicidal Ideation and Behaviors: A Meta-Analysis. Pediatrics 2015; 135(2): e496-e509.

56. Mokdad AH, Forouzanfar MH, Daoud F, et al. Global burden of diseases, injuries, and risk factors for young people's health during 1990-2013: a systematic analysis for the Global Burden of Disease Study 2013. Lancet 2016; 387(10036): 2383-401.

57. Bonell C, Fletcher A, Morton M, Lorenc T. 'Realist Randomised Controlled Trials': a new approach to evaluating complex public health interventions. Soc Sci Med 2012; 75(12): 2299-306. 58. Campbell R, Starkey F, Holliday J, et al. An informal school-based peer-led intervention for smoking prevention in adolescence (ASSIST): a cluster randomised trial. Lancet 2008; 371: 1595-602. 59. Curran T, Wexler L. School-based positive youth development: a systematic review of the literature. Journal of School Health 2017; 87(1): 71-80. 